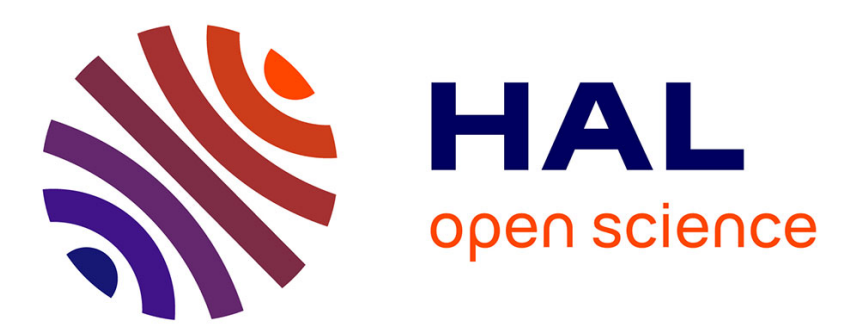

\title{
Single-cell electroporation of adult sensory neurons for gene screening with RNA interference mechanism.
}

Mathieu Boudes, Simon Pieraut, Jean Valmier, Patrick Carroll, Frédérique

Scamps

\section{- To cite this version:}

Mathieu Boudes, Simon Pieraut, Jean Valmier, Patrick Carroll, Frédérique Scamps. Single-cell electroporation of adult sensory neurons for gene screening with RNA interference mechanism.. Journal of Neuroscience Methods, 2008, 170 (2), pp.204-11. 10.1016/j.jneumeth.2008.01.018 . inserm-00257563

\section{HAL Id: inserm-00257563} https://www.hal.inserm.fr/inserm-00257563

Submitted on 19 Feb 2008

HAL is a multi-disciplinary open access archive for the deposit and dissemination of scientific research documents, whether they are published or not. The documents may come from teaching and research institutions in France or abroad, or from public or private research centers.
L'archive ouverte pluridisciplinaire $\mathbf{H A L}$, est destinée au dépôt et à la diffusion de documents scientifiques de niveau recherche, publiés ou non, émanant des établissements d'enseignement et de recherche français ou étrangers, des laboratoires publics ou privés. 


\section{Manuscript (With Page Numbers)}

\section{HAL author manuscript}

Single-cell electroporation of adult sensory neurons for gene screening with RNA interference mechanism

Mathieu Boudes ${ }^{1,2}$, Simon Pieraut ${ }^{1,2}$, Jean Valmier ${ }^{1,2}$, Patrick Carroll ${ }^{1}$ and Frédérique Scamps ${ }^{1}$

${ }^{1}$ Inserm, U583, Montpellier, F-34000 France

${ }^{2}$ Univ Montpellier II, Montpellier, F-34000 France

Key words: Single-cell electroporation, RNA interference, DRG, electrical activity, NKCC1.

\section{Number of text pages: 22}

\section{Number of figures: 5}

Correspondence should be addressed to Dr. Frédérique Scamps, INM-Hôpital St Eloi, Inserm U583, 80, rue Augustin Fliche, 34091 Montpellier Cedex 5, France

E-mail: scamps@univ-montp2.fr

Tel: 33 (0)4 99636033

Fax: $33(0) 499630020$ 


\section{Abstract}

RNA interference appears as a technique of choice to identify gene candidate or to evaluate gene function. To date, a main problem is to achieve high transfection efficiencies on native cells such as adult neurons. In addition, transfection on organ or mass culture does not allow to approach the cellular diversity. Dorsal root ganglia are composed with several cell types to convey somato-sensory sensations. Single-cell electroporation is the most recent method of transfection that allows the introduction into cells, not only dyes or drugs, but also large molecules such plasmid DNA expression constructs. In the present study, the application of the RNA interference technique with the use of single-cell electroporation was evaluated in primary culture of adult sensory neurons. With the use of fluorescent dextran as a co-transfectant, we first determined the non specific siRNA concentration leading to cell death. Efficacy of siRNA at the non toxic concentration was demonstrated at the protein level by extinction of GFP fluorescence in actin-GFP neurons and by the inhibition of the intracellular $\mathrm{Cl}^{-}$concentration increase following activation of the membrane co-transporter $\mathrm{Na}^{+}-\mathrm{K}^{+}-2 \mathrm{Cl}^{-}$in regenerating axotomized sensory neurons. Altogether, these data show that delivery of siRNAs by single-cell electroporation leads to the induction of functional RNA interference. 


\section{Introduction}

Altering gene expression is a widely used methodology to unravel the molecular mechanisms involved in cellular physio-pathology. One way to manipulate gene expression is to introduce plasmids, antisense or small interfering RNA (siRNA) into cells. To date, among the available techniques for gene transfer or inhibition, the most widely used include lipidbased transfection, mass electroporation, calcium phosphate co-precipitation, microinjection and vector delivery. The single-cell electroporation (SCE) is a new approach of transfection that has emerged during the last decade. SCE is an efficient technique used to inject molecules such as dyes (Haas et al., 2001; Graham et al., 2007), calcium indicators (Nagayama et al., 2007; Nevian and Helmchen, 2007) and drugs (Neumann et al., 1999) into cells, both in vitro (Rae and Levis, 2002; Rathenberg et al., 2003) and in vivo (Haas et al., 2001; Bestman et al., 2006; Nagayama et al., 2007). It was shown that delivery of plasmids into cells by SCE leads to its expression a few hours after electroporation (Haas et al., 2001; Rae and Levis, 2002; Rathenberg et al., 2003). This method offers several advantages over the others such as the possibility of using very small quantities of material. It allows the transfection of specific neuronal subsets within a heterogeneous cell population. Finally, a particular region of a cell can be targeted, such as growth cone versus soma. This methodology, combined with siRNA based RNA interference would be a powerful tool to study gene function in specific cell types. However, no data are available concerning the efficiency of this method for gene inhibition with RNA interference.

To validate this technique as a powerful means for transfection of subsets of neurons, we used primary cultures of adult sensory neurons. Indeed, dissociation and culture of adult dorsal root ganglia, DRG, results in a limited number of neurons (in the range of 2000-4000 per ganglion) composed of highly heterogeneous subpopulations of sensory neurons 
responsible for nociception, thermoception, mecanoception and proprioception. Moreover, after a peripheral nerve injury there is a dramatic change in gene expression whose role in the regeneration process of the subsets of neurons is poorly understood (Mechaly et al., 2006). To evaluate the efficiency of RNA interference, we transfected siRNA using SCE into control and axotomized adult sensory neurons in primary culture. We analyzed the siRNA uptake by detecting the rhodamine fluorescence produced by rhodamine tagged siRNA. The neuronal survival was estimated by counting the number of living transfected cells after 3 days in vitro (3 DIV). Membrane integrity and efficiency of the transfection were evaluated by electrophysiological recordings.

We show here that RNA interference mechanism occurs when siRNAs are delivered by SCE into adult sensory neurons in culture.

\section{Materials and methods}

\subsection{Animals and surgery}

Adult female Swiss mice (6-12 weeks old, CERJ, Le Genest St Isle, France) and actingreen fluorescent protein (GFP) mice (Okabe et al., 1997) were housed in cages with a 12/12 light/dark cycle and fed ad libitum. The care and use of mice conformed to institutional policies and guidelines. For analysis of NKCC1 knock down with siRNA, mice were deeply anaesthetized by isoflurane inhalation. The left sciatic nerve was exposed at the mid-thigh level, sectioned and a 3-5 $\mathrm{mm}$ fragment of nerve removed. Mice were kept alive for 4 to 10 days. Mice were killed by $\mathrm{CO}_{2}$ inhalation followed by cervical dislocation. In axotomized DRG, only the ipsilateral L4 and L5 lumbar DRG were removed. 


\subsection{Cell dissociation culture}

Neuron cultures were established from lumbar (L4-L5) dorsal root ganglia, as previously described (Andre et al., 2003). Briefly, ganglia were successively treated by two incubations with collagenase A (1 mg/ml, Roche Diagnostic, France) for $45 \mathrm{~min}$ each and then with trypsin-EDTA (0.25\%, Sigma, St Quentin Falavier, France) for 30 min. They were mechanically dissociated by passing several times through the tip of a fire-polished Pasteur pipette in Neurobasal (Life Technologies, Cergy Pontoise, France) culture medium supplemented with $10 \%$ fetal bovine serum and DNAse (50 U/ml, Sigma). Isolated cells were collected by centrifugation and suspended in Neurobasal culture medium supplemented with 2\% B27 (Life Technologies), $2 \mathrm{mM}$ glutamine and penicillin/streptomycin (20 U/ml, 0.2 $\mu \mathrm{g} / \mu \mathrm{l})$. Dissociated neurons were plated on D-polyornithine $(0.5 \mathrm{mg} / \mathrm{ml})$-laminin $(5 \mu \mathrm{g} / \mathrm{ml})$ coated glass coverslips and were incubated in an incubator with a $95 \%$ air-5\% $\mathrm{CO}_{2}$ atmosphere.

\subsection{Small interfering RNA (siRNA)}

The EGFP-siRNA was purchased from Qiagen (Courtaboeuf, France). The sense strand sequence was 5' GCAAGCUGACCCUGAAGUUCA. It was 3'-rhodamine tagged. Pooled non-targeting control siRNAs (siCONTROL) or specific NKCC1-siRNAs (slc12a2) used in this study were the on-target plus SMART pools from Dharmacon (Perbio Science, Brebières, France; Dharmacon Catalog \# L-O44448-01 targeting NKCC1 (NM_009194)). Stock solutions of siRNA $(20 \mu \mathrm{M})$ were prepared in RNase-free water. All siRNA were diluted into a solution (in $\mathrm{mM}$ ): $145 \mathrm{KCl}, 10$ HEPES. Three $\mathrm{mM}$ dextran-fluorescein (Fisher 
bioblock Scientific, Illkirch Graffenstaden, France) was added into the pipette to visualize transfected neurons.

\subsection{Electroporation}

Four to five hours after plating, neurons were transferred to the stage of an inverted microscope equipped with epifluorescence (TE300, Nikon). Neurons were bathed in a normal Locke solution (in $\mathrm{mM}$ ): $145 \mathrm{NaCl}, 5 \mathrm{KCl}, 2 \mathrm{CaCl}_{2}, 1.5 \mathrm{MgCl}_{2}, 10$ HEPES, 10 Glucose, $\mathrm{pH}$ 7.4 adjusted with $\mathrm{NaOH}$. Glass electrodes were pulled on a micropipette puller (model P-97, Sutter Instrument Co., USA) using thin-walled $1.5 \mathrm{~mm}$ O.D. filament glass capillary (GC150F-10, Harvard Apparatus, Edenbridge, UK). Electrode tips (roughly $1 \mu \mathrm{m}$ in diameter and $15 \mathrm{M} \Omega$ resistance) were filled with $10 \mu \mathrm{l}$ dextran-fluorescein/siRNA. Electroporation was accomplished using a stimulator S88B (Grass medical instrument, Quincy, USA). We tested various electroporation protocols and kept the protocol that afforded the highest survival rate. The optimal protocol consisted of a one sec, $200 \mathrm{~Hz}$ train of $1 \mathrm{~ms}$ square pulses at $+10 \mathrm{~V}$. After siRNA electroporation, neurons were transferred to culture media and maintained for 72 hours in the incubator prior to experiments.

\subsection{Cell fixation and image analysis}

Three days after siRNA electroporation, cultured neurons were fixed with $4 \%$ paraformaldehyde in PBS for 10 min. The slides were then washed in PBS before mounting in aqueous medium. Images were collected using a PL-Apochromat 20x/0.8 objective on an upright Zeiss microscope equipped with a CDD camera AxioCam MRm (Zeiss, Le Pecq, 
France). Image acquisition was done using Axio Vision (Zeiss) and analysis with Metamorph 7.0 (Molecular Devices).

\subsection{Electrophysiology}

Electrophysiological recordings in DRG neurons were done at room temperature, after 3 DIV. For membrane resting potential and the action potential recordings, bathing solution was (in $\mathrm{mM}$ ): $140 \mathrm{NaCl}, 5 \mathrm{KCl}, 2 \mathrm{CaCl}_{2}, 1.5 \mathrm{MgCl}_{2}, 10$ Glucose, 10 HEPES; and the $\mathrm{pH}$ was adjusted to 7.4 with $\mathrm{NaOH}$. Recording pipettes were filled with the following solution (in $\mathrm{mM}): 140 \mathrm{KCl}, 10$ HEPES, $2 \mathrm{Mg}$-ATP, $0.5 \mathrm{Na}_{2}$-GTP, 0.1 EGTA; pH 7.35, adjusted with $\mathrm{KOH}$.

The intracellular chloride concentration, $\left[\mathrm{Cl}^{-}\right]_{\mathrm{i}}$, was measured with the perforatedpatch technique (Pieraut et al, 2007). Briefly, external $\mathrm{NaCl}$ and $\mathrm{KCl}$ were replaced with tetraethylammonium (TEA)-Cl, plus $100 \mu \mathrm{M} \mathrm{CdCl}_{2}$ and $100 \mu \mathrm{M} \mathrm{NiCl}_{2}$ to inhibit high and low voltage-activated $\mathrm{Ca}^{2+}$ channels, respectively ( $\mathrm{pH}$ adjusted with $\mathrm{CsOH}$ ). In the pipette, $\mathrm{KCl}$ was replaced with $\mathrm{CsCl}$. Gramicidine A (Fluka, Saint Quentin Fallavier, France) (50 $\mu \mathrm{g} / \mathrm{ml}$ ) was added to the pipette solution. The progress of gramicidine perforation was evaluated by monitoring the capacitive transient produced by a $10 \mathrm{msec}$ depolarizing voltage step $(10 \mathrm{mV})$ from a $-80 \mathrm{mV}$ holding potential. With $50 \mu \mathrm{g} / \mathrm{ml}$ gramicidin, the access resistance dropped to $30-40 \mathrm{M} \Omega$ within 15 min of seal formation and then remains stable. Then, $500 \mathrm{~ms}$ ramp protocols from $-80 \mathrm{mV}$ to $+40 \mathrm{mV}$ were applied to the cell every $5 \mathrm{sec}$. After 3 trials to ensure that ramp current was steady, a puff of muscimol $(100 \mu \mathrm{M})$ was applied to determine the reversal potential of $\mathrm{Cl}^{-}$currents (Sigma, Saint Quentin Fallavier, France). Muscimol activated a chloride current in all sensory neurons due to $\mathrm{GABA}_{\mathrm{A}} \mathrm{R}$ 
activation. The $\left[\mathrm{Cl}^{-}\right]_{\mathrm{i}}$ was calculated using the Nernst equation: $\mathrm{E}_{\mathrm{rev}}=\mathrm{RT} / \mathrm{ZT} \times\left(\log \left(\left[\mathrm{Cl}^{-}\right] \mathrm{i} /\left[\mathrm{Cl}^{-}\right.\right.\right.$ ] $)$, where $\mathrm{RT} / \mathrm{ZF}=58 \mathrm{mV}$ at room temperature and $\left[\mathrm{Cl}^{-}\right]_{\mathrm{e}}=147 \mathrm{mM}$.

Currents were recorded with an Axopatch 200B amplifier (Molecular Devices, Dipsi Industrie, Chatillon). The experimental parameters were controlled with a computer equipped with a Digidata 1200 analogue interface. We used pClamp software (Clampex 8.2; Molecular Devices) for data acquisition and analysis. Signals were filtered at $2 \mathrm{kHz}$ and sampled at 4 $\mathrm{kHz}$. Glass electrodes (3-4 M $\Omega$ ) were made from capillary glass, and coated with paraffin to minimize pipette capacitance.

\subsection{Statistical analysis}

All results were expressed as mean \pm standard error of the mean (s.e.m). Statistical comparisons were made with one-way analysis of variance (ANOVA) with the post-hoc Newmann-Keuls test or with Student's $t$-test to identify significant differences. In all cases, $p$ $<0.05$ was considered significant.

\section{Results}

\subsection{Survival of electroporated neurons}

Sensory neurons displayed different soma sizes that are somewhat associated with different sensory modalities (Lawson, 1992). Roughly, nociceptors are found mainly among the small-sized neurons (20-30 $\mu \mathrm{m}$ soma diameter, $60 \%$ of cell population), proprioceptors and mechanoreceptors are represented primarily in the medium and large diameter groups. To 
ensure as much as possible homogeneity in the results, we focused our study on the mediumsized neurons. For transfection, viable neurons were selected according to their cell body refringence, lack of vacuoles when observed under a phase contrast $10 \mathrm{X}$ objective. The electrode was brought toward the soma at a $45^{\circ} \mathrm{C}$ angle and positioned in the middle with the use of a micromanipulator (Fig.1A). We estimated that the contact between neuron and electrode was sufficient for electroporation when a small deflection of the membrane was observed on electrode application. To visualize online the single cell electroporation process, dextran-fluorescein was added to the solution containing siRNA (Fig. 1B, D). After 3 DIV, dextran-fluorescein was still present in electroporated neurons and had spread into neurites (Fig. 1C). To ensure that dextran-fluorescein by itself did not prevent the transfer of siRNA into cell cytoplasm, we also monitored transfection efficacy of a rhodamine tagged siRNA (red) together with dextran-fluorescein (green). We found that all electroporated neurons fluoresced red and green $(\mathrm{n}=16$, not shown). Therefore both dextran-fluorescein and siRNA enter into the cell.

Afterwards, we evaluated the survival rate of neurons electroporated with pipettes filled with dextran-fluorescein. To estimate neuronal survival of the culture, the number of neurons was counted with a $10 \mathrm{X}$ objective along a vertical axis passing through the center of the coverslip (6 fields). Counts were made at 4 and at 72 hours following plating. Electroporation was performed 4 hours after plating and number of electroporated neurons was noted. Three days after the electroporation, the survival rate of electroporated neurons was estimated by counting the number of remaining fluorescent relative to control conditions (Fig. 2). The survival rate of non transfected neurons at 3 DIV was $75 \pm 3 \%,(n=125$ from 2 wells, one culture). Electroporation with dextran-fluorescein did not significantly modify neuronal survival ( $59 \pm 1.2 \%, \mathrm{n}=35$ from 3 cultures). As it was not possible to know the exact volume of solution injected in a cell, we next determined the minimal concentration of 
siRNA in the electrode that induced cell death. Cell electroporation with $1 \mu \mathrm{M}$ siCONTROL, a non-fluorescent-tagged siRNA, together with dextran-fluorescein did not significantly modify neuronal survival $(63 \pm 2.9 \%, \mathrm{n}=79)$. Increasing siRNA concentration to $3 \mu \mathrm{M}$ and $10 \mu \mathrm{M}$ induced significant cell death. The survival was $43 \pm 5.3 \%(\mathrm{n}=41)$ and $12 \pm 6.3 \%(\mathrm{n}$ =26), 3 days after electroporation with $3 \mu \mathrm{M}$ and $10 \mu \mathrm{M}$ siCONTROL, respectively (Fig. 2). We concluded that concentrations of siRNA less than $3 \mu \mathrm{M}$ would not adversely affect sensory neuron survival.

\subsection{Inhibitory effect of $R N A_{i}$-targeting GFP transcript in mouse actin-GFP sensory neurons}

In a second series of experiments, instead of co-transfection of siRNA with fluorescent dextran, we used a tagged siRNA to visually confirm the efficacy of siRNA delivery with SCE and its efficiency at the non toxic concentration, i.e. $1 \mu \mathrm{M}$. We transfected mouse actinGFP adult sensory neurons with $1 \mu \mathrm{M}$ rhodamine tagged GFP-siRNA to switch off the GFP fluorescence in transfected neurons. In the actin-GFP mouse line, enhanced green fluorescent protein, EGFP, expression is driven by the actin promoter leading to strong GFP fluorescence in most organs (Okabe et al., 1997). In primary culture, all cell types, neuron and glia, remained GFP tagged (see Fig. 3A). As noted above, on-line visualization of electroporation confirmed that siRNA entered all electroporated neurons. Three days after electroporation, red fluorescence of the siRNA in neurons was still detectable (Fig. 3B) and cell counting showed no difference in neuronal viability compared to siCONTROL transfected neurons. To check whether the RNAi-targeting effect was effective, the intensity of GFP fluorescence of rhodamine tagged EGFP-siRNA was compared to dextran-siCONTROL electroporated neurons. As illustrated Figure 3, EGFP-siRNA transfected neurons display a decrease in their GFP fluorescence. Analysis of fluorescence intensity between EGFP-siRNA and 
siCONTROL injected neurons show a significant $40 \%$ decrease in GFP fluorescence in EGFP-siRNA-treated neurons (Fig. 3D). Interestingly, the satellite cells (arrow, Fig 3A) that surrounded transfected neurons were not affected by the $\mathrm{RNA}_{i}$ mechanism (see Fig. $3 \mathrm{C}$ ). Taken together, these data show that single-cell electroporation is an efficient method to introduce siRNA into adult sensory neurons in primary culture and we provide evidence that non toxic concentration of siRNA is able to produce specific inhibitory effects.

\subsection{Effects of siRNA concentration on electrophysiological properties of sensory neurons}

Although neuronal death is a commonly used parameter to evaluate siRNA specificity, cell death alone is insensitive to physiological dysfunctions that may fall short of toxicity. However, cell excitability is a sensitive means of assessing changes in membrane integrity. To determine whether the passive and active neuronal electrophysiological parameters were affected by the electroporation protocol and siRNA transfection, we recorded resting membrane potential (RMP) and action potentials (AP) of naive and transfected adult sensory neurons. Neurons displaying progressive depolarization of RMP were excluded from the analysis. As stated above, to ensure cell homogeneity, we recorded the medium-sized neurons (Fig. 4A). No differences were observed in membrane capacity of the neurons whatever the protocol used (Fig. 4B). RMP was measured under current clamp $(\mathrm{I}=0)$, and was around - 55 $\mathrm{mV}$ in neurons recorded after 3 DIV. This value was not modified by SCE with dextranfluorescein $3 \mathrm{mM}$, nor with siCONTROL at 1 and $3 \mu \mathrm{M}$ (Fig. 4C). Estimation of the neuron excitability was done by measuring the threshold current necessary to trigger an AP. After 3 DIV, threshold current amplitude was $1.2 \pm 0.2 \mathrm{nA}, \mathrm{n}=7$ and this value was not significantly changed by dextran-fluorescein electroporation, nor with the addition of siCONTROL at 1 $\mu \mathrm{M}$. In the presence of $3 \mu \mathrm{M}$ siCONTROL, the amplitude of threshold current was increased 
to $1.9 \pm 0.2 \mathrm{nA}, \mathrm{n}=11$, but not significantly different from other experimental conditions

(Fig. 4D). Finally, the peak amplitude of the action potential was not modified whatever the experimental condition (Fig. 4E).

Our results show that delivery of siRNA by electroporation can be toxic at concentrations greater than $3 \mu \mathrm{M}$. However, at this concentration surviving sensory neurons remain viable by physiological measures.

\subsection{Inhibitory effect of RNAi-targeting $N K C C 1$ on the intracellular chloride concentration}

To validate the SCE methodology for specific subpopulation targeting, we transfected the medium-sized neurons belonging to the population of regenerating axotomized neurons. Axotomized neurons represent roughly $50-60 \%$ of neurons in culture after a conditioning sciatic nerve section in vivo (Andre et al., 2003). Recently, we demonstrated that in addition to their mode of growth, axotomized sensory neurons are characterized by a neurite initiation, measured as a neurite length longer than one cell diameter, that begins 4 to 5 hours after cell dissociation compared to at least $12 \mathrm{~h}$ for non-axotomized neurons (Pieraut et al., 2007). Accordingly, to ensure that we were specifically analyzing regenerating axotomized neurons, 4 hours after cell dissociation, neurons showing neurite initiation were electroporated. To functionally confirm gene knock down with RNAi using SCE, we used a previously validated NKCC1-siRNA (Pieraut et al., 2007). NKCC1 is a membrane protein involved in the cotransport of $\mathrm{Na}^{+}-\mathrm{K}^{+}-2 \mathrm{Cl}^{-}$into sensory neurons. Estimation of the intracellular concentration of $\mathrm{Cl}^{-}$ions, $\left[\mathrm{Cl}^{-}\right]_{\mathrm{i}}$, is a method to measure the activity of $\mathrm{NKCC}$. We have shown that axotomy induces an increase in the activity of NKCC1, leading to a nearly 2 fold increase in $\left[\mathrm{Cl}^{-}\right]_{\mathrm{i}}$. We estimated the $\left[\mathrm{Cl}^{-}\right]_{\mathrm{i}}$ by measuring the reversal potential of the GABA-A $\mathrm{Cl}^{-}$current, $\mathrm{E}_{\mathrm{GABA}-\mathrm{A}}$, activated with the specific GABA-A receptor agonist muscimol (see methods, Fig. 5A). As 
previously reported (Pieraut et al., 2007), control lumbar DRG neurons display significantly more hyperpolarized $\mathrm{E}_{\mathrm{GABA}-\mathrm{A}}$ than axotomized neurons $(-39.7 \pm 1.6 \mathrm{mV}, \mathrm{n}=10$ and $-24.5 \pm$ $2.1 \mathrm{mV}, \mathrm{n}=8$, respectively, $\mathrm{p}<0.01$ Student's $t$-test). From measurement of $\mathrm{E}_{\mathrm{GABA}-\mathrm{A}}$ after 3 DIV, the calculated $\left[\mathrm{Cl}^{-}\right]_{\mathrm{i}}$ was $32 \pm 2 \mathrm{mM}(\mathrm{n}=10)$ and $53 \pm 5 \mathrm{mM}(\mathrm{n}=8)$ in control and regenerating axotomized neurons, respectively. SCE of axotomized neurons with $1 \mu \mathrm{M}$ siCONTROL and $3 \mathrm{mM}$ dextran-fluorescein did not significantly modify the increase in $\left[\mathrm{Cl}^{-}\right]_{\mathrm{i}}$ in axotomized neurons. However, 3 days after single-cell electroporation of $1 \mu \mathrm{M}$ NKCC1siRNA, $\left[\mathrm{Cl}^{-}\right]_{\mathrm{i}}$ recorded in axotomized neurons was not significantly different from control neurons ( $35 \pm 3 \mathrm{mM}, \mathrm{n}=18)$. The corresponding depolarizing shift of the Erev of axotomized neurons was significantly suppressed at $1 \mu \mathrm{M}$ but not at $0.5 \mu \mathrm{M}$ siRNA ( $<<0.01$; Fig. 5B). Altogether, these data show that siRNA delivery by SCE is a suitable method to induce functional gene knock down.

\section{Discussion}

In the present study, we show that the siRNA single-cell electroporation method is efficient for gene inhibition in adult medium-sized sensory neurons in vitro.

The main question to answer in this study was to determine the effective concentration of the siRNA in SCE experiments necessary for specific gene silencing. Our methodology was to first determine the concentration leading to cell toxicity because siRNA-induced toxicity is RNAi-dependent and the result of off-target gene modulation (Fedorov et al., 2006). The viability of the neurons following electroporation was evaluated by counting their neuronal survival at 3 DIV and analyzing their excitability. Besides the limited neuronal death that naturally occurs following the dissociation procedure, neither the voltage protocol for electroporation nor the addition of dextran-fluorescein induced significant supplementary cell 
death. We show that a siCONTROL concentration of $1 \mu \mathrm{M}$ in the electrode is the maximal concentration that did not induce cell death. At $3 \mu \mathrm{M}$ siCONTROL, toxicity does occur in 20 $\%$ of neurons which could be related to a greater concentration of siRNA transfected into these neurons. Such results suggest that despite a cell selection based on somatic size, sensory neurons are not uniformly transfected. Obviously, concentration of siRNA in the pipette is not the actual cytoplasmic concentration. Indeed, cytoplasmic siRNA concentration is the ratio of volume injected versus cell volume. The volume injected depends on the voltage protocol applied and on the tip of the pipette. Both parameters were electronically controlled and thus reproducible. Although we selected a neuronal subpopulation with a somatic diameter in the range $30-40 \mu \mathrm{m}$, the volume of each neuron is unknown. Thus, cell geometry is an important parameter that has to be taken into account when performing SCE. Whatever the cell type, toxicity appears to be the most objective criteria for selecting siRNA working concentrations. Altogether our data show that, under our experimental conditions, $1 \mu \mathrm{M}$ siRNA is the maximal concentration in the pipette to be tested for specific gene silencing.

As our study was focused on the possibility to use single transfected neurons for subsequent electrophysiological studies, we analyzed cell excitability parameters as general measures of cell viability. We show that cell excitability seems less sensitive to non specific effects of siRNA compared to neuronal death, since at $3 \mu \mathrm{M}$ siCONTROL there was a significant increase in cell death and the remaining neurons presented no changes in the electrophysiological parameters analyzed (resting membrane potential and action potential). As discussed above, this could be related to the actual concentration of injected siRNA that would be less in the remaining neurons. Surprisingly, at high concentration of siCONTROL $(10 \mu \mathrm{M})$, the membrane parameters affected were probably related to membrane elasticity or charge. Indeed, the lack of cell excitability analysis in this condition was related to the impossibility of achieving a high resistance contact between electrode and cell membrane. 
Our data show that single-cell delivery of siRNA modified neither the mechanisms involved in the RMP nor the action potential parameters. This observation leads to the conclusion that SCE of siRNA is possible in a range of concentration below $3 \mu \mathrm{M}$ in the electrode in which electrophysiological study could be done after siRNA delivery.

In the present study, the functionality of the $\mathrm{RNA}_{\mathrm{i}}$ mechanism was evaluated at the protein level estimated either visually (GFP expression) or functionally (intracellular chloride concentration measurement). Analysis of GFP expression shows that we could induce a $40 \%$ decrease in GFP fluorescence with SCE of EGFP-siRNA. To further analyze RNAi mechanism, we tried to demonstrate a dose-effect relationships between NKCC1-siRNA and $\left[\mathrm{Cl}^{-}\right]_{\mathrm{i}}$. At $0.5 \mu \mathrm{M}$ NKCC1-siRNA we could not induce a significant decrease in $\left[\mathrm{Cl}^{-}\right]_{\mathrm{i}}$ and at 1 $\mu \mathrm{M}$ we got a nearly maximal inhibition of the increase in $\left[\mathrm{Cl}^{-}\right]_{\mathrm{i}}$ induced by axotomy. We did not perform experiments with $3 \mu \mathrm{M}$ si-NKCC1 as we demonstrated toxicity in $20 \%$ of neurons with a siCONTROL. Such apparent all or nothing effects could be due to a protein expression not linearly related to transcript quantity. In addition, we analyzed the variations in $\left[\mathrm{Cl}^{-}\right]_{\mathrm{i}}$ which are not directly linked to NKCC1 expression but to NKCC1 activity. Our experiments show that, under our conditions, the critical step between loss of function and protein expression was reached with a decrease in transcript induced with $1 \mu \mathrm{M} \mathrm{NKCC1-}$ siRNA. The outcome of these successive cellular events is an apparent narrow range of concentrations between siRNA efficacy and toxicity when analyzing NKCC1 activity. In addition to the evaluation of the off-target effects, measurement of the silencing effect at the mRNA level is also an important and reliable indication of siRNA-mediated silencing efficiency. Complementary strategies, such as single-cell qRT-PCR, could confirm this point and help to quantify the relationships between transcript quantity and protein expression or activity (Fink et al., 1998). 
Besides screening for candidate genes, siRNA SCE opens a large field of applications. This methodology would be helpful for the study of the diversity and the characterization of the dorsal root ganglia neurons. Somato-sensory neurons are divided in subpopulations which convey different sensory modalities (Lawson, 1992). Morphological identification of subpopulations in vitro is a subject of intensive research and SCE should be useful to explore the molecular identification of functional markers, such the calcium-activated chloride current expressed in medium-sized sensory neurons after nerve injury (Andre et al., 2003). Numerous proteins are the product of several genes. For example, the low voltage activated calcium currents can be generated by three different genes that are difficult or impossible to discriminate with pharmacological tools (Lee et al., 1999; Ertel et al., 2000). The SCE method should complement examinations, at the cellular level, of the functional import of genes expressed in specific subsets of sensory neurons; for example, the expression of Cav 3.2 in Down-hair mechanoreceptors (Dubreuil et al., 2004; Aptel et al., 2007). Moreover, the study of sensory information processing is possible by co-culture of spinal cord/sensory neurons (Bird, 1985; Jahr and Jessell, 1985; Vikman et al., 2001) or keratinocytes/sensory neurons (Ulmann et al., 2007). SCE adds a powerful tool to investigate the molecules involved during sensory information processing and integration by allowing the inhibition of pre or postsynaptic molecules that may be critical to neuronal excitability. It was recently suggested that small siRNAs could diffuse via gap junctions to adjacent cells (Valiunas et al., 2005). In the present study, it appears that this did not occur, at least in vitro, as evidenced by the lack of fluorescent siRNA in the satellite cells surrounding neurons. This raises the possibility of investigating paracrine effects that might occur between cell types in DRG culture. The RNA mechanism is widely used to screen genes involved in an intracellular pathway. That screening could be now done at the single-cell level without any interference of the surrounding cells. Moreover, Lovell et al (2006) transfected Aplysia california growth cones, 
which means that it is now possible to down regulate the gene expression in a subcellular localization. SCE could also be used to do a functional screening of candidate genes from a transcriptomic study.

Taken together, this study demonstrates that single-cell electroporation makes possible the delivery of siRNA into chosen neurons in vitro to down regulate gene expression by $\mathrm{RNA}_{\mathrm{i}}$. SCE can be a powerful means to study physiological pathways in sensory neurons in vitro.

\section{Acknowledgments}

The work was supported by the Association Française contre les Myopathies (AFM), and the Ministère de la Recherche. We thank Dr Hassan Boukhaddaoui and the technical support of the regional imaging platform (MRI). 
References

Andre S, Boukhaddaoui H, Campo B, Al-Jumaily M, Mayeux V, Greuet D, Valmier J, Scamps F Axotomy-induced expression of calcium-activated chloride current in subpopulations of mouse dorsal root ganglion neurons. J Neurophysiol, 2003, 90:3764-73.

Aptel H, Hilaire C, Pieraut S, Boukhaddaoui H, Mallie S, Valmier J, Scamps F The Cav3.2/alpha1H T-type Ca2+ current is a molecular determinant of excitatory effects of GABA in adult sensory neurons. Mol Cell Neurosci, 2007, 36:293-303.

Bestman JE, Ewald RC, Chiu SL, Cline HT In vivo single-cell electroporation for transfer of DNA and macromolecules. Nat Protoc, 2006, 1:1267-72.

Bird MM Establishment of synaptic connections between explants of embryonic neural tissue in culture: experimental ultrastructural studies. Exp Brain Res, 1985, 57:337-47.

Dubreuil AS, Boukhaddaoui H, Desmadryl G, Martinez-Salgado C, Moshourab R, Lewin GR, Carroll P, Valmier J, Scamps F Role of T-type calcium current in identified D-hair mechanoreceptor neurons studied in vitro. J Neurosci, 2004, 24:8480-4.

Ertel EA, Campbell KP, Harpold MM, Hofmann F, Mori Y, Perez-Reyes E, Schwartz A, Snutch TP, Tanabe T, Birnbaumer L, Tsien RW, Catterall WA Nomenclature of voltage-gated calcium channels. Neuron, 2000, 25:533-5.

Fedorov Y, Anderson EM, Birmingham A, Reynolds A, Karpilow J, Robinson K, Leake D, Marshall WS, Khvorova A Off-target effects by siRNA can induce toxic phenotype. Rna, 2006, 12:1188-96.

Fink L, Seeger W, Ermert L, Hanze J, Stahl U, Grimminger F, Kummer W, Bohle RM Realtime quantitative RT-PCR after laser-assisted cell picking. Nat Med, 1998, 4:1329-33.

Graham LJ, Del Abajo R, Gener T, Fernandez E A method of combined single-cell electrophysiology and electroporation. J Neurosci Methods, 2007, 160:69-74.

Haas K, Sin WC, Javaherian A, Li Z, Cline HT Single-cell electroporation for gene transfer in vivo. Neuron, 2001, 29:583-91.

Jahr CE, Jessell TM Synaptic transmission between dorsal root ganglion and dorsal horn neurons in culture: antagonism of monosynaptic excitatory postsynaptic potentials and glutamate excitation by kynurenate. J Neurosci, 1985, 5:2281-9.

Lawson S (1992) Morphological and biochemical cell types of sensory neurons. In: Sensory Neurons. Diversity, Development, and Plasticity (SA S, ed), pp 27-59. New York: Oxford University Press.

Lee JH, Gomora JC, Cribbs LL, Perez-Reyes E Nickel block of three cloned T-type calcium channels: low concentrations selectively block alpha1H. Biophys J, 1999, 77:3034-42. 
Mechaly I, Bourane S, Piquemal D, Al-Jumaily M, Venteo S, Puech S, Scamps F, Valmier J, Carroll $\mathrm{P}$ Gene profiling during development and after a peripheral nerve traumatism reveals genes specifically induced by injury in dorsal root ganglia. Mol Cell Neurosci, 2006, 32:217-29.

Nagayama S, Zeng S, Xiong W, Fletcher ML, Masurkar AV, Davis DJ, Pieribone VA, Chen WR In vivo simultaneous tracing and $\mathrm{Ca}(2+)$ imaging of local neuronal circuits. Neuron, 2007, 53:789-803.

Neumann E, Kakorin S, Toensing K Fundamentals of electroporative delivery of drugs and genes. Bioelectrochem Bioenerg, 1999, 48:3-16.

Nevian T, Helmchen F Calcium indicator loading of neurons using single-cell electroporation. Pflugers Arch, 2007, 454:675-88.

Okabe M, Ikawa M, Kominami K, Nakanishi T, Nishimune Y 'Green mice' as a source of ubiquitous green cells. FEBS Lett, 1997, 407:313-9.

Pieraut S, Laurent-Matha V, Sar C, Hubert T, Mechaly I, Hilaire C, Mersel M, Delpire E, Valmier J, Scamps F NKCC1 phosphorylation stimulates neurite growth of injured adult sensory neurons. J Neurosci, 2007, 27:6751-9.

Rae JL, Levis RA Single-cell electroporation. Pflugers Arch, 2002, 443:664-70.

Rathenberg J, Nevian T, Witzemann V High-efficiency transfection of individual neurons using modified electrophysiology techniques. J Neurosci Methods, 2003, 126:91-8.

Ulmann L, Rodeau JL, Danoux L, Contet-Audonneau JL, Pauly G, Schlichter R Trophic effects of keratinocytes on the axonal development of sensory neurons in a coculture model. Eur J Neurosci, 2007, 26:113-25.

Valiunas V, Polosina YY, Miller H, Potapova IA, Valiuniene L, Doronin S, Mathias RT, Robinson RB, Rosen MR, Cohen IS, Brink PR Connexin-specific cell-to-cell transfer of short interfering RNA by gap junctions. J Physiol, 2005, 568:459-68.

Vikman KS, Backstrom E, Kristensson K, Hill RH A two-compartment in vitro model for studies of modulation of nociceptive transmission. J Neurosci Methods, 2001, 105:175-184. 


\section{Legends}

Figure 1. Visualization of SCE in real-time and after 3 DIV. A dextran-fluorescein was filled into the micopipette. (A) Phase contrast showing the pipette tip in contact with the cell membrane of a sensory neuron. (B) Fluorescence image of the cell shown in (A) $15 \mathrm{~ms}$ after electroporation. (C) Another sensory neuron, from the same culture at 3DIV, filled with dextran-fluorescein after electroporation. Note fluorescence in the cell body and neurites (D) Fluorescence images during electroporation of neuron shown in (A) and (B) are shown at the indicated time points (in ms) after starting the pulse. Scale bar, $35 \mu \mathrm{m}$.

Figure 2. Transfected neurons survival is dependent on the siRNA concentration.

Transfection of non-targeting siRNA (siCONTROL, $1 \mu \mathrm{M}$ ) has no effect on the survival of the transfected neurons compared to the transfection of the vehicle (dextran-fluorescein, 3 $\mathrm{mM}$ ) and to the non transfected neurons. The increase of the siCONTROL concentration to 3 and $10 \mu \mathrm{M}$ induces a significant decrease in survival rate. Number of counted neurons is in bracket. (ns $=$ not significant; $* \mathrm{p}<0.05 ; * * * \mathrm{p}<0.001$; ANOVA)

Figure 3. Inhibitory effect of $\mathrm{RNA}_{\mathrm{i}}$-targeting GFP levels in mouse actin-GFP sensory neurons.

(A) Photograph (GFP filters) of transfected (arrowhead) and non transfected (asterix) mouse actin-GFP sensory neurons and (arrow) satellite cell at 3DIV in primary cultures. Neurons were electroporated 4 hours after cell dissociation with $1 \mu \mathrm{M}$ rhodamine tagged GFP-siRNA. Note peripheral localization of GFP in satellite cells (arrow) surrounding rhodamine-siRNA containing neurons. (B) Same neurons observed with rhodamine filters show red fluorescence filling the cytoplasm of transfected neurons. (C) The overlay of A and B shows the 
colocalisation of the siRNA against GFP and the down regulated GFP neurons. (D) At 3DIV, GFP average intensity was analyzed off line with metamorph software and expressed in arbitrary unit (AU). GFP mean intensity was significantly decreased in EGFP-siRNA transfected compared to siCONTROL electroporated $(31 \pm 3 \mathrm{AU}, \mathrm{n}=28$ and $52 \pm 4 \mathrm{AU}, \mathrm{n}=$ 26 , respectively; ${ }^{* * *} \mathrm{p}<0.001$, Student's $t$ test). (Scale bar in A, B, C: $35 \mu \mathrm{M}$ ).

Figure 4. Transfected neurons do not display different electrophysiological characteristics.

(A) Medium-sized neurons were selected for the study. Prior to electrophysiological measurements, neuron was selected by measuring its somatic diameter with a micrometer positioned in the ocular of the microscope. (B) Membrane capacitance measurements confirm size homogeneity. (C) Resting membrane potential measured at 3 DIV was not significantly modified by the siRNA up to $3 \mu \mathrm{M}$. (D) The amplitude of the threshold current that triggers a fast action potential, (E) the maximal amplitude of the action potential, peak value were not significantly modified by the siRNA up to $3 \mu \mathrm{M}$. Inset, action potential trace and current injection protocol.

Figure 5. Inhibitory effect of RNAi-targeting $\mathrm{NKCC} 1$ on the $\mathrm{E}_{\mathrm{GABA}} \mathrm{A}$

Gramicidin-based perforated patch-clamp recordings were used to determine $\left[\mathrm{Cl}^{-}\right]_{\mathrm{i}}$. The reversal potential of $\mathrm{Cl}^{-}$currents was determined by applying $500 \mathrm{~ms}$ ramp protocols from -80 $\mathrm{mV}$ to $+40 \mathrm{mV}$. (A) Typical current traces recorded under $\mathrm{Na}^{+}, \mathrm{K}^{+}$and $\mathrm{Ca}^{2+}$ currents inhibition at 3 DIV in an axotomized sensory neuron. In this neuron, puff application of supramaximal concentration of muscimol $(100 \mu \mathrm{M})$ induces an increase in the slope conductance, which reverses at $-23 \mathrm{mV}$. (B) $\mathrm{E}_{\mathrm{GABA}-\mathrm{A}}$ in axotomized lumbar DRG neurons was $-24.5 \pm 2.1 \mathrm{mV}(\mathrm{n}=8)$. Transfection of $1 \mu \mathrm{M}$ siCONTROL did not affect the value of the $\mathrm{E}_{\mathrm{GABA}-\mathrm{A}}(-25.3 \pm 1.8 \mathrm{mV}, \mathrm{n}=9)$. At $0.5 \mu \mathrm{M}$ NKCC1-siRNA, $\mathrm{E}_{\mathrm{GABA}-\mathrm{A}}$ was not significantly 
modified $(-26.8 \pm 2.3, \mathrm{n}=7)$. The effects of axotomy on the $\left[\mathrm{Cl}^{-}\right]_{\mathrm{i}}$ was inhibited following the single-cell transfection of $1 \mu \mathrm{M}$ of NKCC1-siRNA $(-35.4 \pm 1.7 \mathrm{mV}, \mathrm{n}=18)$. (** p value $<$ 0.01; one way ANOVA). 


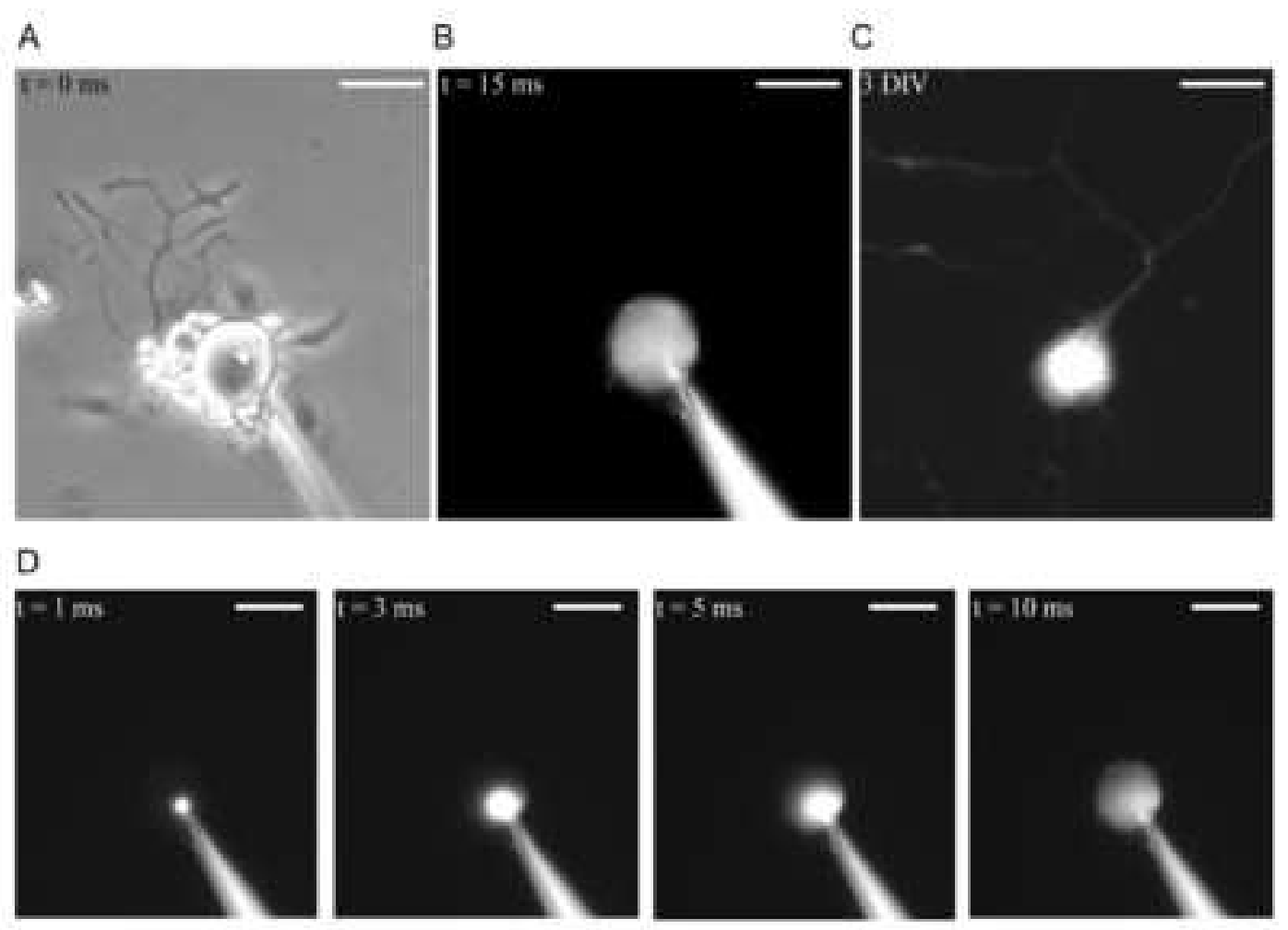

Page 23 of 27 


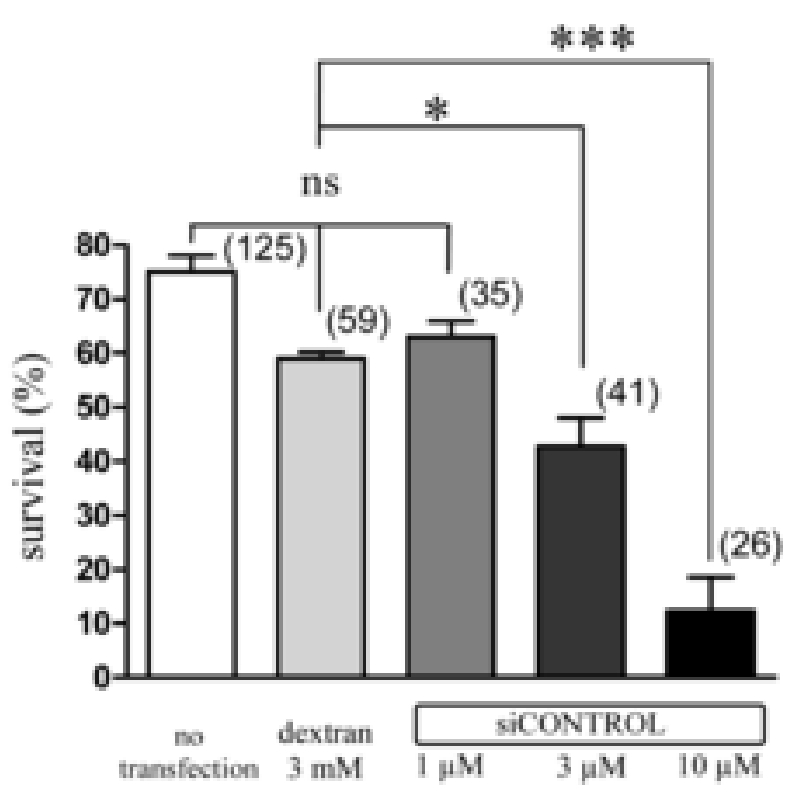

Page 24 of 27 


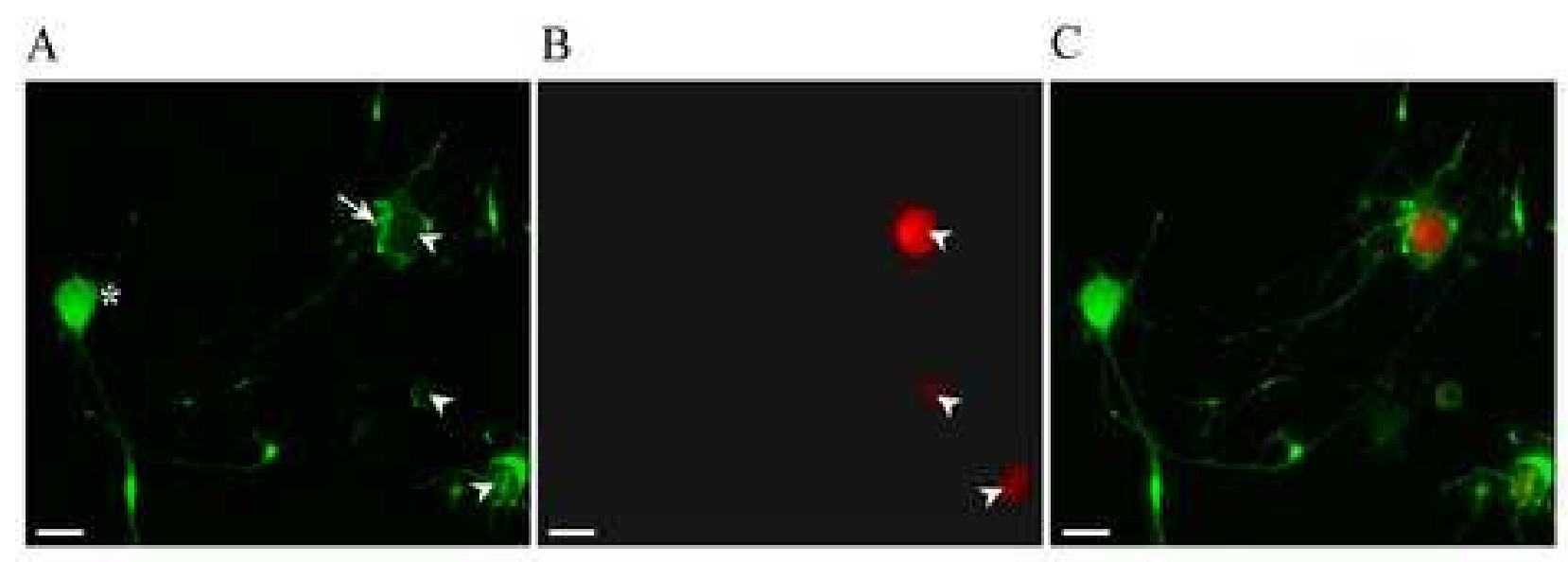

D

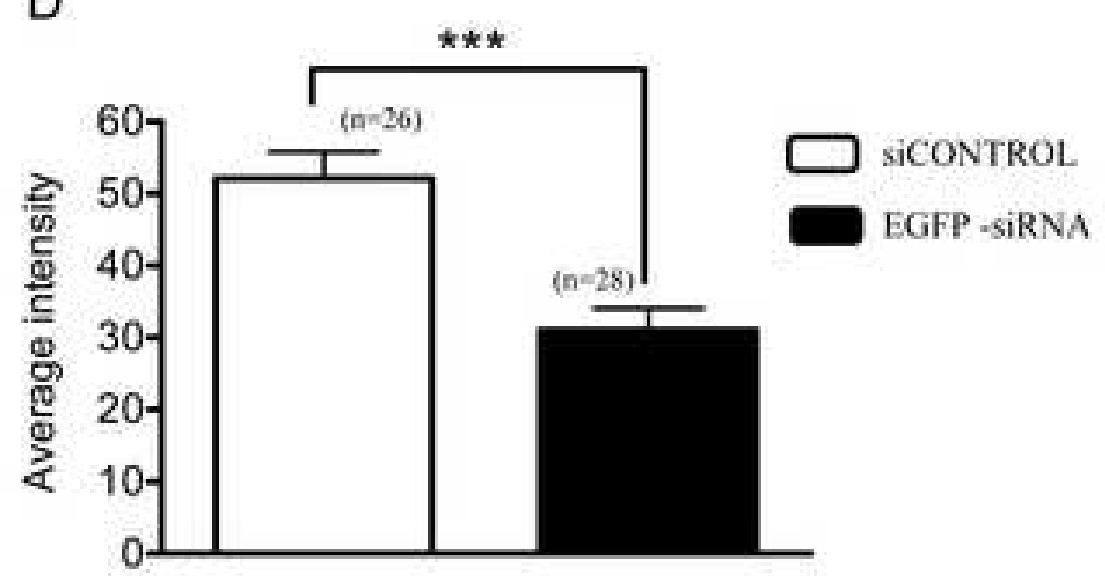

Page 25 of 27 


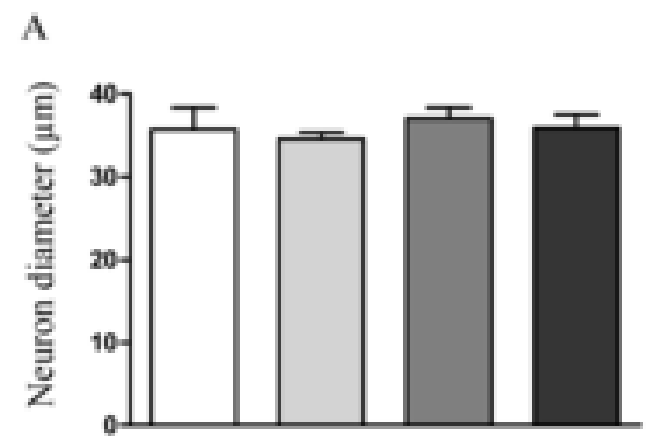

B

C
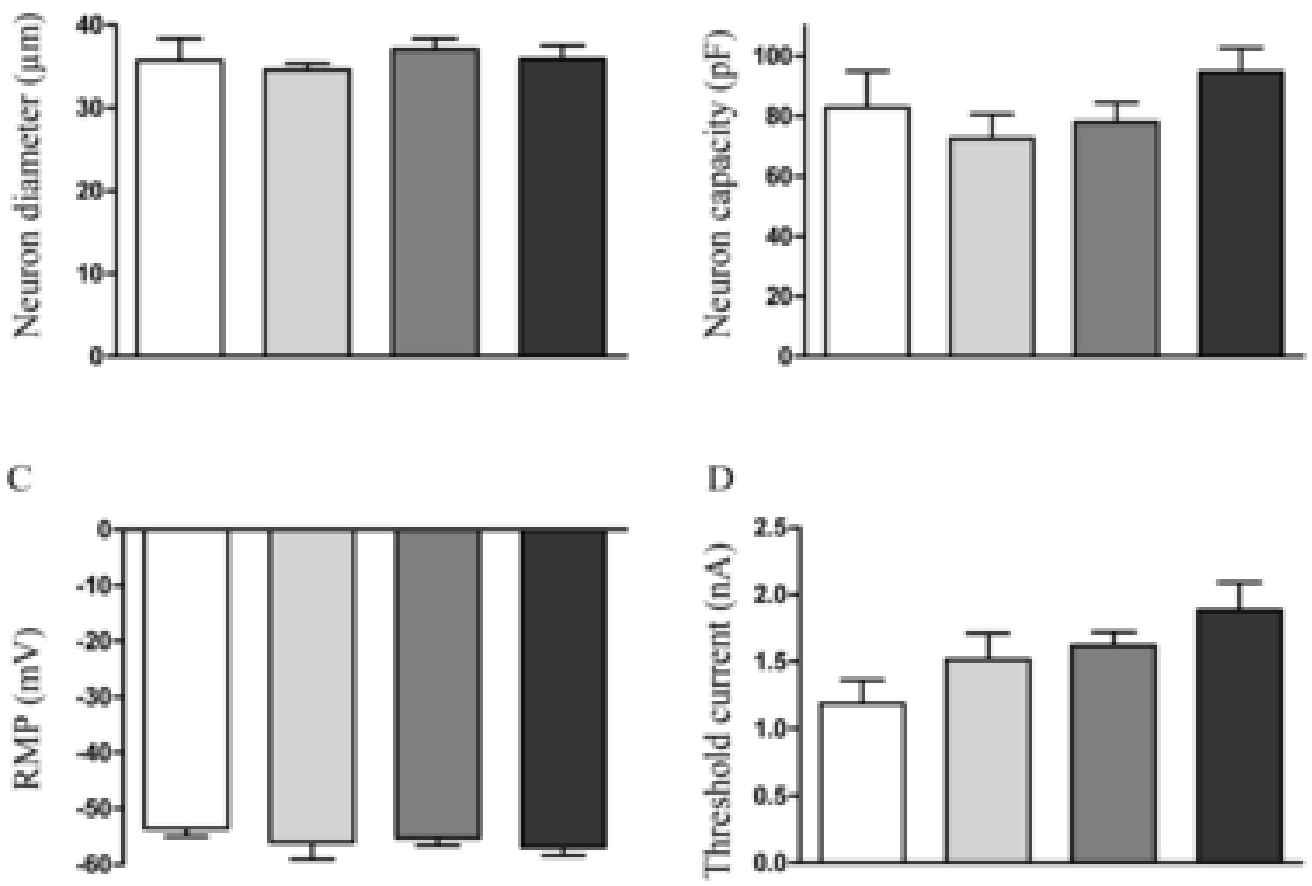

D

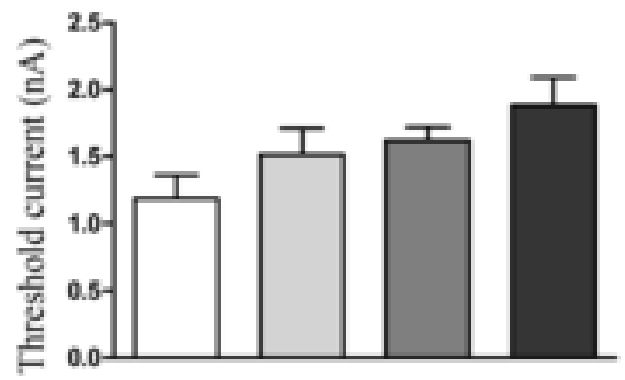

E

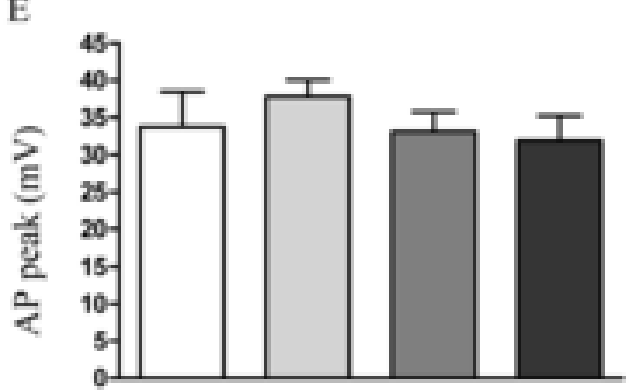




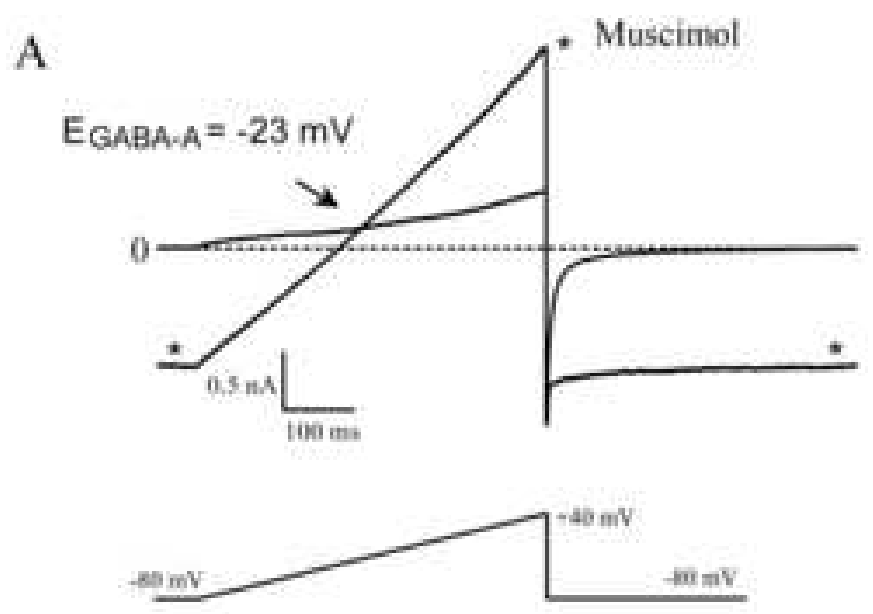

B
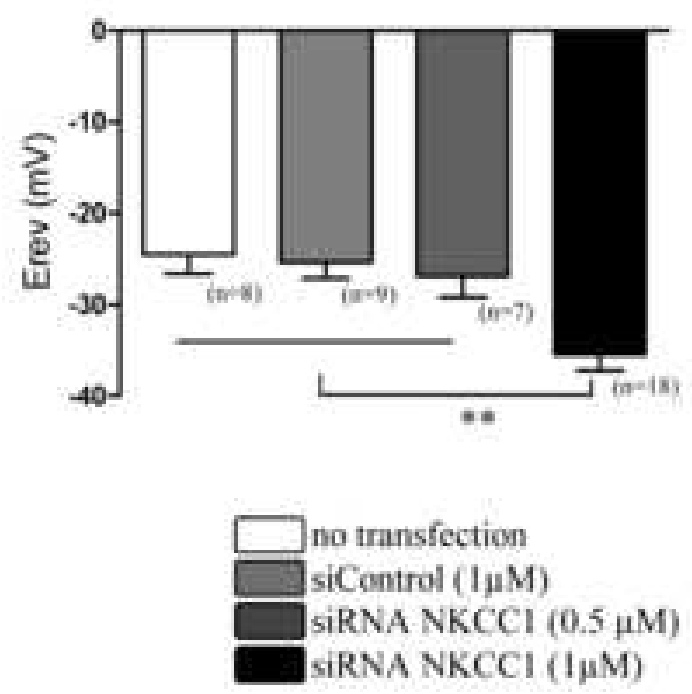

Page 27 of 27 